\title{
Cambios en el estatus social de las mujeres casadas en la España del siglo xx
}

Carolina Montoro Gurich

Universidad de Navarra

\section{RESUMEN}

En este trabajo se analizan los cambios de la posición social de las mujeres según trabajen o no fuera del hogar en España, entre 1916 y 1991. La fuente empleada es la Encuesta Sociodemográfica de 1991. La posición social del marido proporciona la posición relativa de la mujer. Los resultados resaltan la importancia del nivel de estudios de la mujer para su posición en el mercado matrimonial y la depreciación del valor conyugal de la mujer ama de casa frente a la mujer trabajadora.

Palabras clave: Mujeres Casadas, Mujeres Trabajadoras, Estatus Social, Cambio Social. 


\section{INTRODUCCIÓN}

Esta investigación tiene como objetivo rastrear los cambios que, durante el siglo xx, se han producido en la consideración social de las mujeres españolas casadas según sean trabajadoras o amas de casa. Sin entrar en el tema de la medición de la movilidad social de la mujer, cuestión sobre la que se ha planteado un debate tan interesante como prolongado ${ }^{1}$, en este estudio la posición social del marido es la que facilita la de la mujer.

Partimos de la idea de que el estatus de esposa ama de casa se ha ido depreciando con el paso del tiempo. A principios del siglo xx, el que la mujer permaneciera en el hogar era signo de buena posición social y de nivel cultural elevado y, en consecuencia, trabajaban más frecuentemente fuera del hogar las mujeres que pertenecían a clases sociales más bajas. El trabajo extradoméstico femenino era más importante entre los estratos sociales menos acomodados, todo ello en un contexto generalizado de mujer ama de casa y, no hay que olvidarlo, de una importante cantidad de trabajo no reconocido por estar en la economía sumergida. En este sentido destaca la actividad femenina en las tareas del campo, lógico habida cuenta de la historia económica de nuestro país, pero no podemos olvidar la actividad remunerada desarrollada también por las mujeres en otros sectores ${ }^{2}$.

Sin embargo, en los años noventa del siglo xx se han invertido los papeles: trabajan fuera del hogar -en una proporción significativamente superior- las mujeres que tienen una buena posición social y un elevado nivel de estudios. Desde el punto de vista del matrimonio, las mujeres casadas con hombres pertenecientes a los estratos sociales medio-altos trabajan fuera del hogar más que las mujeres casadas con hombres pertenecientes a los estratos sociales inferiores; el trabajar fuera del hogar se ha convertido, en sí mismo, en un factor de prestigio social, o quizá sería más acertado señalar que el permanecer en el hogar y ser exclusivamente ama de casa no es una tarea que goce de prestigio social ${ }^{3}$.

Se va a indagar sobre esta cuestión, difícil de explicar sin caer en estereotipos. Se trata de medir, con la información disponible en la ESD, el valor matrimonial o conyugal de las mujeres a lo largo del tiempo. Valor es, según el Diccionario de la Lengua Española de la Real Academia Española, una «cualidad que poseen algunas realidades, consideradas bienes, por lo cual son estimables». Desde el punto de vista matrimonial, un hombre de clase alta tiene mayor valor que un hombre de clase baja, porque tiene o se espera que reúna toda

\footnotetext{
1 R. Feito Alonso (1995); J. Echeverría Zabalza (1997); O. Salido (1998).
}

2 Entre la abundante bibliografía que recoge esta realidad citaremos, a modo de ejemplo, A. Moreno Almárcegui (1998); M. J. Birriel Salcedo (1998); M. D. García Ramón et al. (1995); G. Canoves Valiente (1992).

3 I. Alberdi, P. Escario y N. Matas (2000). 
una serie de bienes: económicos, culturales, sociales, poder... y una mujer casada con un hombre de clase social alta tiene un valor conyugal mayor que una mujer casada con un hombre de clase social baja, porque se asume que los hombres de estatus alto se casan con las mujeres que tienen mayores potencialidades.

Se está haciendo referencia a la lógica que impera en el establecimiento de lazos efectivos entre las personas: una persona busca en su eventual pareja ciertos atributos, valores, etc., que considera más apetecibles, importantes o mejores... y acaba uniéndose a alguien relativamente semejante a sí mismo, al menos en cuanto a sus características más objetivas o sencillas de comparar ${ }^{4}$. En este texto no se trata de realizar un análisis del mercado matrimonial, entre otras cosas porque estas personas llevan casadas, al menos, 16 años (los que tiene su hijo). Sin embargo, parece lógico esperar una cierta coherencia interna en estas parejas que llevan conviviendo todos estos años.

Un problema al que nos enfrentamos a la hora de exponer nuestros resultados es el lenguaje: somos conscientes de que algunas frases pueden dar la impresión de instrumentalizar a las personas y las relaciones efectivas de las mismas. En nuestra defensa señalamos que en este trabajo las mujeres se convierten en sujetos estadísticos.

Las preguntas que nos planteamos son: 1) ¿cuándo se ha producido este cambio en el valor matrimonial de las esposas según trabajen o no fuera del hogar?, y 2) ¿qué clases sociales han iniciado y/o protagonizado este cambio? Más concretamente, ¿pueden señalarse diferencias significativas adoptando el punto de vista de clases situadas en extremos de la escala social?

\section{ASPECTOS METODOLÓGICOS}

\subsection{Dimensión temporal del análisis}

La información más rica y completa de la ESD es la que se refiere a ego, el sujeto entrevistado, pero se ha optado por centrar el análisis en sus progenitores por diversas razones. En primer lugar, los egos disponen, estadísticamente de forma abrumadora, de padre y madre, con lo que la información sobre los dos miembros de la pareja estaba asegurada y, además, se amplía el número de casos disponibles para analizar. En segundo lugar, la información de los dos padres de ego se sitúa en el momento en el que ego tenía 16 años, lo que significa que la información es comparable para todas las generaciones de egos al co-

4 Citaremos como ejemplo las obras de J. Carabaña (1983); J. Iglesias de Ussel (1987); M. Bozon (1990a, 1990b, 1991, 1992); A. Cabré (1993). 
rresponder al mismo momento vital ${ }^{5}$. Se puede asumir que cuando ego tenía esta edad su padre estaba en el momento de plenitud profesional y, en el caso de la madre, su situación como ama de casa o trabajadora fuera del hogar estaba claramente establecida. Y, finalmente, se obtiene una mayor amplitud temporal. La perspectiva que se consigue analizando la información sobre ego iría, aproximadamente, de $1940^{6}$ a 1991 , mientras que empleando la referida a sus padres nos permite remontarnos a 1916.

\subsection{Variables}

Las variables empleadas en este análisis son: "generación de nacimiento de ego», "clase social del padre», «actividad laboral de la madre» y «nivel de estudios de la madre».

La generación de nacimiento de ego vertebra la dimensión histórica de toda la información. En este análisis las generaciones se han establecido de diez en diez años, tomando como punto de partida 1900. La excepción es la última generación, que sólo comprende cinco años, de 1971 a 1975 . Esto significa que las décadas que se analizan, correspondientes al momento en el que los egos tenían 16 años, se extienden desde 1916 hasta 1991.

La escala de clase social, elaborada según el esquema de Erikson y Goldthorpe, está formada por: clase de servicio, trabajadores de rutina no manuales, burguesía urbana, burguesía campesina, trabajadores especializados, trabajadores no especializados en la industria y los servicios, y trabajadores no especializados en el sector primario.

La variable «actividad laboral de la madre» ha sido definida en dos categorías: mujeres que trabajan fuera de casa y mujeres amas de casa. Finalmente, el «nivel de estudios de la madre» sirve de variable de control. La escala de estudios, de menor a mayor nivel, es la siguiente: analfabeta, alfabeta, estudios de primer grado, estudios de segundo grado y estudios superiores.

\subsection{El Índice de Valor Conyugal (IVC) de las mujeres}

Se ha elaborado un índice con el objetivo de comparar el valor conyugal de las mujeres trabajadoras con el valor conyugal de las mujeres amas de casa.

\footnotetext{
5 A pesar del amplio abanico de edades a las que los padres tuvieron a ego, y de las diferentes situaciones familiares (ego puede ser el primer o último hijo), el análisis de las edades de los padres proporciona medianas muy estables para todas las generaciones, entre 47-50 años para los padres y 44-46 años para las madres.
}

6 Asumiendo que tomamos la información de ego en el momento en que tenía 40 años. 
En este punto retomamos la definición de «valor conyugal» de la mujer definiéndolo, objetivamente, desde dos perspectivas: en primer lugar, desde una perspectiva personal, plasmada en el nivel de estudios que tiene la mujer; en segundo lugar, el valor conyugal de la mujer tiene una dimensión matrimonial, por cuanto que la posición social del marido es, tal como se ha señalado, la que nos proporciona la posición social de la mujer. Para simplificar nuestro análisis, sólo se toma en consideración a las mujeres casadas con hombres situados en los dos extremos de la escala social. Por un lado, los incluidos en los estratos medio-altos o «clase de servicio» $y$, por otro, los que de forma abreviada denominaremos «proletariado»: aquellos clasificados en «burguesía campesina», «trabajadores no especializados en la industria y los servicios» y «trabajadores no especializados en el sector primario» 7 .

Tomando a las mujeres casadas con el mismo nivel de estudios de estos dos grupos se calcula la proporción de amas de casa casadas con hombres de clase alta sobre el total de amas de casa consideradas y, por otro lado, la proporción de mujeres trabajadoras casadas con hombres de clase alta sobre las trabajadoras en cada generación ${ }^{8}$.

\section{HIPÓTESIS DE TRABAJO}

1) La mujer ama de casa ha experimentado un declive de su valor matrimonial a lo largo del siglo $x x$.

2) La mujer que trabaja fuera del hogar ha experimentado un aumento de su valor matrimonial a lo largo del siglo xx.

3) Las clases altas son las que inician el proceso de cambio del estatus matrimonial femenino según su actividad laboral.

4) El nivel de estudios de la mujer actúa como proxy de su destino matrimonial: a mayor nivel de estudios, más alta es la clase social de su marido.

5) La unión de los factores «mayor nivel de estudios» y «trabajo extradoméstico» en la mujer está asociada a matrimonio con hombre situado en la cúspide social.

\footnotetext{
7 El criterio utilizado para unir estas tres clases está desarrollado en C. Montoro (2003).

8 El apéndice recoge los valores del IVC. Las pruebas del chi-cuadrado indican que las diferencias entre las proporciones son estadísticamente significativas $(P=0,01)$.
} 


\section{LA SITUACIÓN LABORAL DE LA MUJER CASADA Y MADRE EN ESPAÑA A LO LARGO DEL SIGLO XX}

En este epígrafe se presenta el grupo de población objeto de nuestro estudio: las mujeres casadas, madres de egos entrevistados en la ESD, que vivieron a lo largo del siglo xx, según su situación laboral cuando ego tenía 16 años. Entre 1916 y 1991, más de ocho de cada diez mujeres están clasificadas como amas de casa y apenas dos de cada diez aparecen clasificadas como trabajadoras fuera del hogar. Sólo en el último período, entre 1987 y 1991, se produce un incremento significativo de la proporción de mujeres trabajadoras fuera del hogar, hasta suponer casi tres de cada diez.

Este panorama evolutivo no es representativo de las mujeres españolas en general. En primer lugar, por la edad; estas mujeres tienen entre 44 y 46 años. En segundo lugar, por la situación familiar de estas mujeres: están casadas y tienen, al menos, un hijo adolescente (ego). Recordemos que la característica más sobresaliente de la trayectoria vital femenina española durante el siglo $x \mathrm{x}$ ha sido la de abandonar el trabajo extradoméstico (en el caso de que lo tuviera) al casarse $y / o$ tener hijos $^{9}$, características ambas que cumple nuestra población de referencia.

\section{EL NIVEL DE ESTUDIOS DE LA MUJER CASADA Y MADRE EN ESPAÑA A LO LARGO DEL SIGLO XX}

Tal como se ha señalado en un epígrafe anterior, el nivel de estudios de la mujer casada es empleado como proxy del valor personal de la mujer. Desde esta perspectiva, es interesante conocer cuál era el nivel de estudios de nuestra población de referencia y si existen diferencias apreciables según se trate de mujeres amas de casa o trabajadoras fuera del hogar. El cálculo de la media del nivel de estudios de los padres de ego según actividad laboral de la madre y su evolución confirma las ideas previas con las que se iniciaba este trabajo.

La correlación entre el nivel de estudios del padre y de la madre de ego ${ }^{10}$ nos permite medir la importancia de la homogamia educativa, y podemos anticipar que al emplear el nivel de estudios de la madre de ego como valor personal estamos también considerando, siquiera de forma implícita, el valor personal del padre de ego.

\footnotetext{
9 Este hecho es especialmente marcado en el caso de las mujeres con bajas cualificaciones académicas (L. Garrido, 1993, p. 133).

10 La correlación de Pearson es igual a 0,724, significativa con una confianza del $99 \%(\mathrm{P}=0,01)$.
} 
TABLA 1

Media del nivel de estudios de los padres de ego según actividad laboral de la madre

\begin{tabular}{|c|c|c|c|c|c|}
\hline \multirow[b]{2}{*}{ Generación ego } & \multirow[b]{2}{*}{ Década } & \multicolumn{2}{|c|}{ Nivel estudios madre } & \multicolumn{2}{|c|}{ Nivel estudios padre } \\
\hline & & Trabajadora & Ama de casa & $\begin{array}{r}\text { Madre } \\
\text { Trabajadora }\end{array}$ & $\begin{array}{r}\text { Madre } \\
\text { ama de casa }\end{array}$ \\
\hline 1 & $1916-1926$ & 1,66 & 1,74 & 1,83 & 1,97 \\
\hline 2 & 1927-1936 & 1,72 & 1,78 & 1,86 & 2,01 \\
\hline 3 & $1937-1946$ & 1,85 & 1,85 & 1,98 & 2,07 \\
\hline 4 & 1947-1956 & 1,93 & 1,93 & 2,07 & 2,15 \\
\hline 5 & $1957-1966$ & 2,21 & 2,12 & 2,32 & 2,35 \\
\hline 6 & $1967-1976$ & 2,38 & 2,24 & 2,45 & 2,48 \\
\hline 7 & $1977-1986$ & 2,60 & 2,33 & 2,66 & 2,56 \\
\hline 8 & 1987-1991 & 3,19 & 2,63 & 3,24 & 2,84 \\
\hline
\end{tabular}

NOTA:

Las medias se han elaborado considerando que ser analfabeto equivale a 1, alfabeto a 2, tener estudios de primer grado a 3 , estudios de segundo grado a 4 , y ser diplomado, licenciado o doctor a 5 puntos.

\section{LA ACTIVIDAD LABORAL DE LA MUJER CASADA Y MADRE SEGÚN LA CLASE SOCIAL DEL MARIDO}

Una primera impresión sobre cuál es la relación entre la actividad laboral de la mujer casada y madre (de ego) y la clase social de su marido (o padre de ego) nos la proporciona la correlación entre estas dos variables ${ }^{11}$.

El gráfico 1 ilustra el hecho de que a principios de siglo el porcentaje de mujeres casadas y con hijos que trabajaban fuera del hogar era poco importante, a lo que se añade que existen acusadas diferencias según la clase social del marido. Cuanto más alta es la clase social de éste, menos trabajaba la mujer fuera del hogar.

La tabla 2 aporta la información en la que se basa el gráfico para tener dimensionada la población con la que se trabaja. El gráfico recoge la proporción de mujeres trabajadoras sobre el total de mujeres para cada clase social del marido y generación.

Las diferencias en los porcentajes de actividad según clase social del marido se van a mantener prácticamente durante todo el período, aunque variarán de signo ostensiblemente a partir de la segunda mitad de los años setenta, cuando no sólo comienza a incrementarse de forma notable el porcentaje de mujeres casadas que trabajan, sino que, además,

\footnotetext{
11 La correlación de Pearson es igual a 0,038, significativa con una confianza del $99 \%(P=0,01)$.
} 


\section{GRÁFICO 1}

Mujeres trabajadoras según clase social del marido y generación

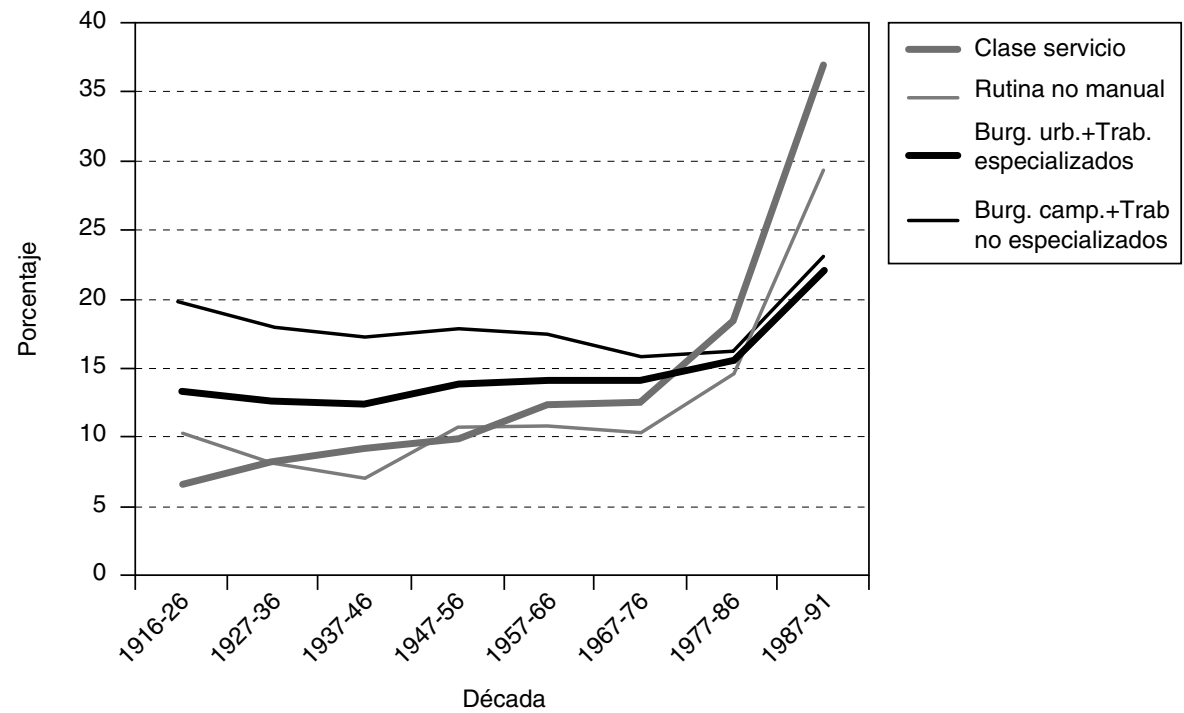

Elaboración propia a partir de los datos de la ESD. INE, 1991.

\section{TABLA 2}

Distribución de las mujeres casadas (trabajadoras fuera del hogar y total) según clase social del marido por décadas

\begin{tabular}{rrrrrrrrr} 
& \multicolumn{3}{c}{ Clase servicio } & \multicolumn{2}{c}{ Rutina no manual } & \multicolumn{2}{c}{ Burg. urb.+Trab. esp. Burg. camp.+Trab. no esp. } \\
\cline { 2 - 9 } Década & Trab. & Total & Trab. & Total & Trab. & Total & Trab. & Total \\
\hline $1916-26$ & 35 & 529 & 20 & 194 & 134 & 1.003 & 780 & 3.963 \\
$1927-36$ & 120 & 1.458 & 40 & 493 & 372 & 2.930 & 1.745 & 9.674 \\
$1937-46$ & 192 & 2.099 & 59 & 836 & 594 & 4.788 & 2.426 & 13.960 \\
$1947-56$ & 170 & 1.714 & 79 & 734 & 575 & 4.155 & 2.023 & 11.285 \\
$1957-66$ & 259 & 2.105 & 110 & 1.011 & 627 & 4.409 & 1.536 & 8.790 \\
$1967-76$ & 413 & 3.313 & 212 & 2.044 & 1.106 & 7.846 & 1.758 & 11.120 \\
$1977-86$ & 643 & 3.502 & 342 & 2.346 & 1.449 & 9.366 & 1.607 & 9.900 \\
$1987-91$ & 1.426 & 3.856 & 751 & 2.556 & 1.980 & 8.932 & 1.436 & 6.221
\end{tabular}


se transforma la relación entre el trabajo de la mujer y la clase social del marido: cuanto más alta es la clase social de éste, más trabaja la mujer, incluso más que las mujeres de las clases trabajadoras.

Así pues, la impresión es que cuanto más nos acercamos al presente, y por tanto a una sociedad moderna, los individuos mejor situados socialmente tienen esposas trabajadoras, 0 , desde otra perspectiva, las mujeres trabajadoras están casadas con hombres bien situados, en una proporción significativamente superior a las mujeres amas de casa.

\section{LOS CAMBIOS EN EL VALOR CONYUGAL DE LAS MUJERES}

El hecho de que durante el período analizado el trabajo fuera del hogar no constituyera un ideal social, unido a que durante la época franquista en particular se fomentara la vuelta de las mujeres al hogar y se hiciera muy difícil su situación en el mercado de trabajo remunerado $^{12}$ (especialmente para las mujeres casadas y con hijos, las protagonistas de nuestro análisis), hacen que, en buena lógica, esperemos encontrar en el mercado de trabajo dos grupos diferenciados de mujeres. Por un lado, mujeres con bajos niveles de estudios casadas con hombres de los estratos sociales más bajos, un grupo que tendría una fuerte motivación económica para seguir trabajando fuera del hogar; por otro, mujeres con altos niveles de estudios casadas con hombres de estratos sociales altos, que trabajarían, podemos hipotetizar, como forma de realización personal. Sin embargo, ¿hasta qué punto es este un planteamiento corroborado por los datos empíricos? Más aún, ¿dónde están las fronteras entre unos estratos sociales y otros? ¿Y entre unos niveles de estudios y otros? ¿Es el trabajo extradoméstico un elemento definitorio del destino matrimonial de las mujeres?

Para profundizar en estas cuestiones vamos a comparar la clase social de las mujeres trabajadoras con la de las mujeres amas de casa, tomando como tal clase la clase social a la que pertenecen sus maridos, recordando que para simplificar nuestro análisis se toman en consideración sólo dos clases sociales, la de servicio y el proletariado.

\section{Esposas analfabetas}

Las mujeres analfabetas han tenido a lo largo de todo el período analizado un valor conyugal muy bajo para los hombres de la clase de servicio, independientemente de su estatus como amas de casa o trabajadoras. En lógica consecuencia, y siempre según el ICV cons-

\footnotetext{
12 I. Alberdi, P. Escario y N. Matas (2000, p. 68).
} 
truido, este grupo de mujeres tiene un valor conyugal muy alto entre los hombres del proletariado, asimismo independientemente de su condición laboral.

\section{Esposas alfabetas}

En términos generales, estas mujeres tienen un valor conyugal más elevado que las analfabetas $y$, sin embargo, relativamente bajo para la clase de servicio. Se advierten diferencias entre la mujer alfabeta ama de casa, con un valor conyugal más elevado, y la mujer alfabeta trabajadora. Por otro lado, el IVC de la mujer ama de casa se mantiene estable a lo largo de las décadas analizadas, y cabe señalar un ligero incremento del valor del índice en el caso de la mujer trabajadora.

Todo lo señalado significa que estas mujeres tienen un valor conyugal alto para el proletariado, ligeramente más marcado en el caso de la alfabeta trabajadora.

\section{Esposas con estudios de primer grado}

Las mujeres con estudios de primer grado tienen un valor conyugal muy diferente según sean amas de casa o trabajadoras. En el primer caso, se trata de mujeres con un valor alto y estable a lo largo del tiempo; las mujeres trabajadoras son esposas de la clase de servicio en una proporción sensiblemente inferior, aunque la tendencia a lo largo del siglo es a aumentar su presencia de forma importante, especialmente a partir de la segunda mitad de los años setenta.

Esto significa que, para el proletariado, la mujer trabajadora con estudios de primer grado tenía un valor conyugal más elevado al comienzo del período objeto de nuestro análisis, y que ha ido perdiendo ese valor conforme nos acercamos al presente. En cuanto a la mujer ama de casa con estudios de primer grado, siempre ha tenido un valor conyugal relativamente elevado entre el proletariado (superior al que tenía entre la clase de servicio). Podría afirmarse que se trata de un tipo de cónyuge frecuente tanto entre los hombres de la clase de servicio como entre los hombres del proletariado, aunque domine entre el proletariado.

\section{Esposas con estudios de segundo grado}

Las mujeres con estudios de segundo grado destacan porque constituyen un grupo con un valor conyugal muy elevado entre los varones de clase de servicio. Es conocido el hecho 
de que durante gran parte del siglo $x x$ el segundo grado del nivel de estudios constituía una frontera social muy clara y, en consecuencia, resulta lógico, conociendo los mecanismos del mercado matrimonial, encontrar que los hombres situados en la cúspide de la escala social estén casados con mucha frecuencia con mujeres que tienen estudios de segundo grado o, desde otra perspectiva, las mujeres con este nivel de estudios están bien casadas (como se suele decir en lenguaje popular) en proporción significativamente elevada. Además, la tendencia de fondo es ascendente tanto para las amas de casa como para las trabajadoras.

En la mujer ama de casa, la década caracterizada por el desarrollo económico — de 1957 a 1966 - constituye el clímax de esta tendencia, mientras que a partir de entonces el valor marital de estas mujeres empieza a descender gradualmente. Probablemente, este hecho indica que al alcanzar un mayor nivel de estudios el conjunto de la sociedad, las elites acentuaron su tendencia a tener sus esposas entre las que tenían estudios superiores.

Por otro lado, esta es la primera ocasión en la que las diferencias en el valor conyugal son, para varias generaciones, a favor de la mujer trabajadora. En concreto, durante las generaciones tercera, cuarta y quinta (entre 1937 y 1966) las mujeres trabajadoras constituyen la única opción conyugal presente para los hombres de la clase de servicio.

Este mismo gráfico nos permite, como hemos hecho con los gráficos anteriores, conocer cuál es el valor conyugal de estas mujeres entre los varones del proletariado. Las mujeres con estudios de segundo grado tienen un IVC relativamente bajo entre el proletariado, sobre todo entre las generaciones más cercanas al presente.

\section{Esposas con estudios superiores}

Las mujeres con estudios superiores son, claramente, otra categoría con un elevado valor conyugal entre los varones de la clase de servicio. Además, las líneas del gráfico de las esposas con estudios superiores, sean amas de casa o trabajadoras, muestran una clara tendencia ascendente; en las últimas décadas queda de manifiesto que estas mujeres constituyen la pareja normal (en términos estadísticos) de las elites.

Por otro lado, este es el único gráfico en el que las mujeres amas de casa aparecen por debajo de las trabajadoras - salvo en las tres primeras décadas, y con un escaso margen de diferencia-. Es decir, que aunque en conjunto se trata de mujeres casadas con elites, entre las trabajadoras este hecho es más acentuado. Podría decirse que las elites masculinas tienen su pareja, de forma dominante y más acusada cuanto más nos acercamos al pre- 
sente, entre las mujeres trabajadoras con estudios superiores, quienes constituirían, por tanto y según el índice construido, las mujeres con valor conyugal más elevado.

De lo expuesto se deduce que las mujeres con estudios superiores tienen un valor conyugal relativamente bajo entre el proletariado. Además, se trata de una categoría que ha experimentado una evolución de signo negativo, puesto que cuanto más nos acercamos al presente, más bajo es el IVC.

\section{CONCLUSIONES}

1) El nivel de estudios pesa siempre más en el valor conyugal de la mujer que su condición de ama de casa o trabajadora. Las mujeres con mayores niveles de estudios tienen un valor conyugal más elevado o, en otras palabras, están casadas en mayor proporción con varones de la clase de servicio que las mujeres con menor nivel de estudios.

En efecto, existe una gradación casi perfecta entre «mayor nivel de estudios - mayor proporción de mujeres casadas con clase de servicio», lo que permite dar por válida la hipótesis 4). Se puede señalar la existencia de dos grupos de mujeres según su valor conyugal: por un lado, las analfabetas — verdadera cónyuge prohibida para las elites - y las alfabetas, con muy bajo valor conyugal para la clase de servicio y muy alto para el proletariado, $y$, por otro, las mujeres con estudios de segundo grado y superiores, con un valor conyugal inverso. El grupo de mujeres con estudios de primer grado actúa como categoría de transición.

Esta conclusión corrobora la importancia de la variable educación en el mercado matrimonial; se ha podido comprobar que las mujeres con «dote escolar» de cada grupo social tienen una ventaja comparativa en el mercado matrimonial respecto a las que tienen un nivel de estudios más bajo.

2) Cuanto más alto es el nivel de estudios, más valorada matrimonialmente está la mujer trabajadora. Esta conclusión permite dar por válida nuestra hipótesis 5).

Por otro lado, el hecho de que en los niveles medio-bajos de estudios la posición matrimonial del ama de casa sea superior socialmente a la de la mujer trabajadora, permite matizar que la condición de ama de casa o trabajadora pesa de forma diferente según sea el nivel de estudios.

Se distinguen tres grupos: por un lado, las analfabetas, entre las cuales la condición laboral apenas tiene relevancia; por otro, las alfabetas y las que tienen estudios de primer grado, 
entre las cuales el peso de la condición laboral de la mujer va in crescendo, y, finalmente, las mujeres con estudios de segundo grado y superiores, entre las cuales las diferencias según la situación de trabajo se suavizan hasta casi desaparecer.

3) Asimismo, se planteaba la existencia de un cambio en algún momento del siglo $x x$ en la valoración matrimonial de la mujer según su situación laboral en el sentido de que el ama de casa experimentaría un declive de dicho valor en beneficio de la mujer trabajadora fuera del hogar —hipótesis 1) y 2)—. Pues bien, el análisis realizado no permite dar por válida la primera hipótesis, y no es apenas posible detectar una pérdida del valor conyugal de las mujeres amas de casa.

Quizá, señalar que durante la década de 1947 a 1956 se produce un pequeño descenso del valor matrimonial de las mujeres amas de casa con niveles de estudios de primer y segundo grado y superiores para la clase de servicio, lo que significa que aumenta su valor matrimonial entre el proletariado. Se trata de un período en el que se fomenta desde las instituciones un modelo de mujer tradicional, centrado en su familia y su hogar ${ }^{13}$, que, según parece, tiene más efecto en los estratos humildes de la sociedad que entre los más altos.

Sin embargo, y con respecto a la hipótesis segunda, sí es posible darla por válida, ya que, efectivamente, el valor conyugal de la mujer trabajadora ha aumentado a lo largo del siglo xx para todos los niveles de estudios.

Los resultados no permiten dar por válida la hipótesis 3), aunque se puede añadir como matiz que las mujeres trabajadoras con estudios de segundo grado y superiores, casadas con clase de servicio, presentan índices de valor conyugal más altos que las mujeres amas de casa con las mismas características. A pesar de ello, las diferencias son muy pequeñas y no se pueden extraer conclusiones definitivas.

13 M. C. Agulló Díaz (1997). 


\section{REFERENCIAS BIBLIOGRÁFICAS}

AGULLÓ DÍAZ, M. C. (1997): «Transmisión y evolución de los modelos de mujer durante el franquismo (1951-1970)», en Actas IV Jornadas de Historia y Fuentes Orales, Fundación Santa Teresa-Universidad Complutense, Madrid, pp. 491-502.

ALBERDI, I.; ESCARIO, P., y MATAS, N. (2000): Las mujeres jóvenes en España, Colección Estudios Sociales, n. ${ }^{\circ}$, Fundación La Caixa, Barcelona.

BIRRIEL SALCEDO, M. J. (1998): Estrategias laborales femeninas: trabajo, hogares y educación, Centro de Ediciones de la Diputación de Málaga, Málaga.

BOZON, M. (1990a): «Les femmes et l'écart d'âge entre conjoints: une domination consentie. I. Types d'union et attentes en matière d'écart d'âge», Population, 2, pp. 327-360.

- (1990b): «Les femmes et l'écart d'âge entre conjoints: une domination consentie. II. Modes d'entrée dans la vie adulte et représentations du conjoint», Population, 3, pp. 565-602.

- (1991): «Mariage et mobilité sociale en France», European Journal of Population/Revue Européenne de Démographie, 7, pp. 171-190.

- (1992): «Le choix du conjoint», en F. de Singly (dir.), La famille l'état des savoirs, Éditions La Découverte, Paris, pp. 22-33.

CABRÉ, A. (1993): «Volverán tórtolos y cigüeñas», en L. Garrido Medina y E. Gil Calvo (eds.), Estrategias familiares, Alianza, Madrid, pp. 113-131.

CANOVES VALIENTE, G. (1992): Mujer, trabajo y explotación agraria familiar: un análisis desde la geografía del género, Servicio de Publicaciones de la Universidad Autónoma de Barcelona, Bellaterra.

CARABAÑA, J. (1983): «Homogamia y movilidad social», REIS, 21, pp. 61-81.

ECHEVERRÍA ZABALZA, J. (1997): «La movilidad social de las mujeres y el problema de la unidad de análisis de clase», Revista Internacional de Sociología (RIS), 17, pp. 83-116.

FEITO ALONSO, R. (1995): «Mujeres y análisis de clases», Revista Española de Investigaciones Sociológicas (REIS), 69, pp. 149-171.

GARCÍA RAMÓN, M. D., et al. (1995): Mujer y agricultura en España: género, trabajo y contexto regional, Oikos-Tau, Barcelona.

GARRIDO, L. (1993): Las dos biografías de la mujer en España, Ministerio de Asuntos Sociales, Instituto de la Mujer, Madrid.

IGLESIAS DE USSEL, J. (1987): Sociología del noviazgo en España, Caja General de Ahorros y Monte de Piedad de Granada, Granada.

MONTORO, C. (2003): «Una interpretación del cambio social en España a partir de las escalas de categoría profesional», en C. Montoro, D. López y N. Caparrós (eds.), Implicaciones del cambio social en la familia, Navarra Gráfica Ediciones, Pamplona, pp. 153-172.

MORENO ALMÁRCEGUI, A. (1998): Diversidad regional de los modelos de feminidad en España, Rialp, Madrid.

SALIDO, O. (1998): «El proceso de movilidad: diferencias y peculiaridades de las mujeres y los hombres», texto inédito presentado en el VI Congreso Español de Sociología, A Coruña. 


\section{APÉNDICE}

Mujeres casadas y madres según nivel de estudios, existencia de actividad laboral y matrimonio con varones de clase servicio y proletariado

Mujeres amas de casa casadas con...

Mujeres trabajadoras casadas con...

\begin{tabular}{|c|c|c|c|c|c|c|c|c|}
\hline $\begin{array}{l}\text { Nivel de } \\
\text { estudios } \\
\text { mujer }\end{array}$ & Servicio (a) & Prolet. (b) & Total $(a+b)$ & $\begin{array}{l}\text { Razón: } \\
\text { (a)/total }\end{array}$ & Servicio (a) & Prolet. (b) & Total $(a+b)$ & $\begin{array}{l}\text { Razón: } \\
\text { (a)/total }\end{array}$ \\
\hline \multicolumn{9}{|l|}{$1916-26$} \\
\hline Analf. & 49 & 1.479 & 1.528 & 0,032 & 2 & 380 & 382 & 0,005 \\
\hline Alfabeta & 312 & 1.515 & 1.827 & 0,171 & 19 & 360 & 379 & 0,050 \\
\hline 1르 grado & 121 & 184 & 305 & 0,397 & 7 & 37 & 44 & 0,159 \\
\hline $2^{\circ}$ grado & 5 & 5 & 10 & 0,500 & 2 & 1 & 3 & 0,667 \\
\hline Sup. & 7 & 3 & 10 & 0,700 & 5 & 2 & 7 & 0,714 \\
\hline Total & 494 & 3.183 & 3.677 & 0,134 & 35 & 780 & 815 & 0,043 \\
\hline \multicolumn{9}{|l|}{$1927-36$} \\
\hline Analf. & 144 & 3.377 & 3.521 & 0,041 & 21 & 805 & 826 & 0,025 \\
\hline Alfabeta & 802 & 3.981 & 4.783 & 0,168 & 52 & 832 & 884 & 0,059 \\
\hline 1ㄹ grado & 352 & 559 & 911 & 0,386 & 24 & 99 & 123 & 0,195 \\
\hline $2^{\circ}$ grado & 14 & 4 & 18 & 0,778 & 3 & 1 & 4 & 0,750 \\
\hline Sup. & 26 & 8 & 34 & 0,765 & 20 & 8 & 28 & 0,714 \\
\hline Total & 1.338 & 7.929 & 9.267 & 0,144 & 120 & 1.745 & 1.865 & 0,064 \\
\hline \multicolumn{9}{|l|}{$1937-46$} \\
\hline Analf. & 158 & 4.358 & 4.516 & 0,035 & 30 & 932 & 962 & 0,031 \\
\hline Alfabeta & 1.086 & 6.203 & 7.289 & 0,149 & 83 & 1.251 & 1.334 & 0,062 \\
\hline 1르 grado & 595 & 960 & 1.555 & 0,383 & 37 & 234 & 271 & 0,137 \\
\hline $2^{\circ}$ grado & 25 & 3 & 28 & 0,893 & 8 & 0 & 8 & 1,000 \\
\hline Sup. & 43 & 10 & 53 & 0,811 & 34 & 9 & 43 & 0,791 \\
\hline Total & 1.907 & 11.534 & 13.441 & 0,142 & 192 & 2.426 & 2.618 & 0,073 \\
\hline \multicolumn{9}{|l|}{$1947-56$} \\
\hline Analf. & 107 & 3.025 & 3.132 & 0,034 & 16 & 678 & 694 & 0,023 \\
\hline Alfabeta & 830 & 5.255 & 6.085 & 0,136 & 60 & 1.137 & 1.197 & 0,050 \\
\hline 1라 grado & 522 & 960 & 1.482 & 0,352 & 42 & 199 & 241 & 0,174 \\
\hline $2^{\circ}$ grado & 39 & 6 & 45 & 0,867 & 8 & 0 & 8 & 1,000 \\
\hline Sup. & 46 & 16 & 62 & 0,742 & 44 & 9 & 53 & 0,830 \\
\hline Total & 1.544 & 9.262 & 10.806 & 0,143 & 170 & 2.023 & 2.193 & 0,078 \\
\hline \multicolumn{9}{|l|}{$1957-66$} \\
\hline Analf. & 54 & 1.649 & 1.703 & 0,032 & 11 & 338 & 349 & 0,032 \\
\hline Alfabeta & 872 & 4.459 & 5.331 & 0,164 & 90 & 922 & 1.012 & 0,089 \\
\hline 1ㄹ grado & 746 & 1.128 & 1.874 & 0,398 & 73 & 268 & 341 & 0,214 \\
\hline $2^{\circ}$ grado & 93 & 4 & 97 & 0,959 & 14 & 0 & 14 & 1,000 \\
\hline Sup. & 81 & 14 & 95 & 0,853 & 71 & 8 & 79 & 0,899 \\
\hline Total & 1.846 & 7.254 & 9.100 & 0,203 & 259 & 1.536 & 1.795 & 0,144 \\
\hline
\end{tabular}




\section{APÉNDICE}

\section{Continuación}

Mujeres amas de casa casadas con...

Mujeres trabajadoras casadas con...

\begin{tabular}{|c|c|c|c|c|c|c|c|c|}
\hline $\begin{array}{l}\text { Nivel de } \\
\text { estudios } \\
\text { mujer }\end{array}$ & Servicio (a) & Prolet. (b) & Total $(a+b)$ & $\begin{array}{l}\text { Razón: } \\
\text { (a)/total }\end{array}$ & Servicio (a) & Prolet. (b) & Total $(a+b)$ & $\begin{array}{l}\text { Razón: } \\
\text { (a)/tota }\end{array}$ \\
\hline \multicolumn{9}{|l|}{$1967-76$} \\
\hline Analf. & 47 & 1.577 & 1.624 & 0,029 & 9 & 310 & 319 & 0,028 \\
\hline Alfabeta & 1.150 & 5.866 & 7.016 & 0,164 & 105 & 1.028 & 1.133 & 0,093 \\
\hline 1 er grado & 1.321 & 1.877 & 3.198 & 0,413 & 125 & 397 & 522 & 0,239 \\
\hline $2^{\circ}$ grado & 224 & 19 & 243 & 0,922 & 43 & 8 & 51 & 0,843 \\
\hline Sup. & 158 & 23 & 181 & 0,873 & 131 & 15 & 146 & 0,897 \\
\hline Total & 2.900 & 9.362 & 12.262 & 0,237 & 413 & 1.758 & 2.171 & 0,190 \\
\hline \multicolumn{9}{|l|}{$1977-86$} \\
\hline Analf. & 44 & 1.365 & 1.409 & 0,031 & 5 & 242 & 247 & 0,020 \\
\hline Alfabeta & 958 & 4.957 & 5.915 & 0,162 & 123 & 963 & 1.086 & 0,113 \\
\hline 1르 grado & 1.362 & 1.919 & 3.281 & 0,415 & 207 & 370 & 577 & 0,359 \\
\hline $2^{\circ}$ grado & 316 & 31 & 347 & 0,911 & 79 & 13 & 92 & 0,859 \\
\hline Sup. & 179 & 21 & 200 & 0,895 & 229 & 19 & 248 & 0,923 \\
\hline Total & 2.859 & 8.293 & 11.152 & 0,256 & 643 & 1.607 & 2.250 & 0,286 \\
\hline \multicolumn{9}{|l|}{$1987-91$} \\
\hline Analf. & 12 & 424 & 436 & 0,028 & 2 & 81 & 83 & 0,024 \\
\hline Alfabeta & 525 & 2.353 & 2.878 & 0,182 & 79 & 631 & 710 & 0,111 \\
\hline 1 er grado & 1.303 & 1.896 & 3.199 & 0,407 & 413 & 611 & 1.024 & 0,403 \\
\hline $2^{\circ}$ grado & 372 & 88 & 460 & 0,809 & 311 & 71 & 382 & 0,814 \\
\hline Sup. & 218 & 24 & 242 & 0,901 & 621 & 42 & 663 & 0,937 \\
\hline Total & 2.430 & 4.785 & 7.215 & 0,337 & 1.426 & 1.436 & 2.862 & 0,498 \\
\hline
\end{tabular}


Índice de Valor Conyugal de las mujeres según nivel de estudios y existencia de actividad laboral.

España, 1916-1991
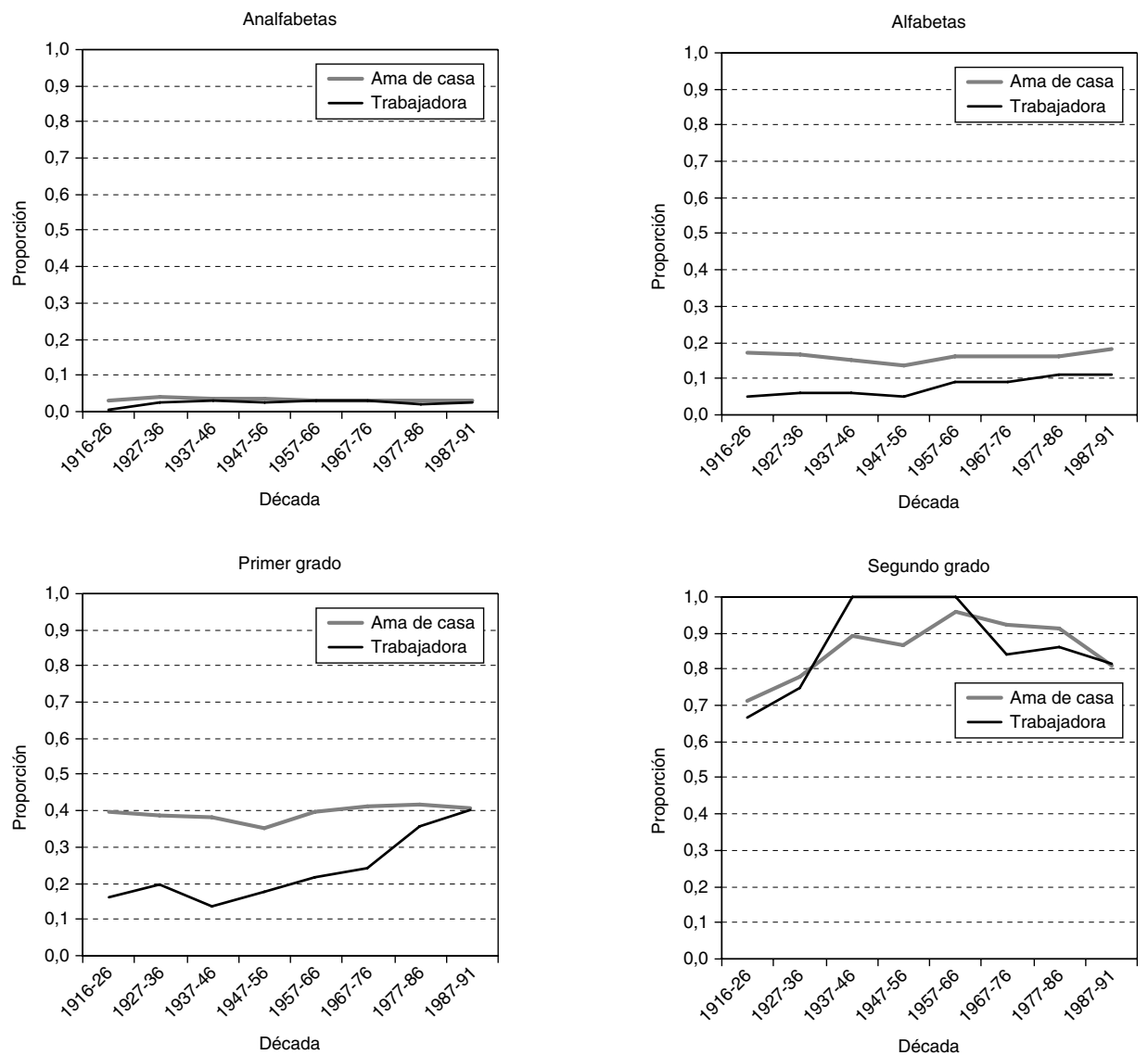

Década

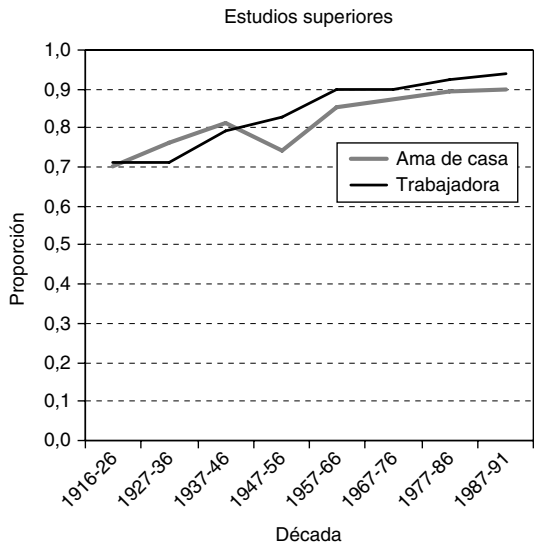




\section{ABSTRACT}

This article analyses the changes of the social position of women according to whether or not they work outside the home in Spain, between 1916 and 1991. The source used is the 1991 Sociodemographic Survey. The social position of the husband provides the position relating to the wife. The results highlight the importance of the woman's educational level for ther position in the marriage market, and the depreciation of the conjugal value of the housewife as compared with that of the working woman.

Key words: Married Women, Working Women, Social Status, Social Change. 